\title{
INSTRUMENTAL NORMATIVITY \\ AND THE PRACTICABLE GOOD: A MURDOCHIAN CONSTITUTIVIST ACCOUNT $^{1}$
}

\author{
EVGENIA MYLONAKI \\ National and Capodistrian University of Athens \\ Department of Philosophy \\ Athens \\ Greece \\ evg.mylonaki@gmail.com
}

\section{Article info \\ CDD: 192 \\ Keywords: \\ Action \\ Instrumental \\ Normativity \\ Constitutivism \\ G. E. M. Anscombe \\ Iris Murdoch \\ Michael Thompson}

Received: 30.08.2018; Accepted: 17.09.2018

DOI: http://dx.doi.org/10.1590/0100-6045.2018.V41N4.EV

\begin{abstract}
In this paper I present a neo-Anscombean account of instrumental normativity and argue against it. I turn to the
\end{abstract}

\footnotetext{
${ }^{1}$ This paper is the outcome of research implemented through the IKY scholarships programme and co-financed by the European Union (European Social Fund - ESF) and Greek national funds through the action entitled "Reinforcement of Postdoctoral Researchers", in the framework of the Operational Programme "Human Resources Development Program, Education and Lifelong Learning" of the National Strategic Reference Framework (NSRF) 2014 - 2020.
} 
writings of Iris Murdoch in order to develop an alternative Anscombean account of instrumental normativity.

\section{INTRODUCTION}

The aim of this paper is to develop a constitutivist account of instrumental normativity (an account of the requirement to take the means to one's end as the normative standard that constitutes intentional action) that overcomes the restrictions of the neo-Anscombean variant of constitutivism without reverting to the reductivism of Kantian constitutivism. I call this account "Murdochian", for it relies on Iris Murdoch's conception of the practicable good. $^{2}$

It is commonly thought that, in intending or acting intentionally, an agent is subject to instrumental norms (norms having to do with (perceived) facts about what the means to our ends are) and telic norms (norms having to do with (perceived) facts about what one ought to do). On the dominant attitudinal picture, an agent is subject to instrumental and telic norms in forming a certain propositional attitude (intention) towards an act which is either one's end or the means to one's end. On the initial narrow-scope interpretation of this picture, an agent is subject to instrumental norms in considering the reasons for intending the means to one's end and to telic norms in considering the reasons for intending an end. ${ }^{3}$ On the refined wide-scope formulation, however, an agent is

\footnotetext{
${ }^{2}$ For substantial help with earlier drafts of this paper I want to thank John McDowell, Kieran Setiya, Matt Boyle, Eric Wiland, Talbot Brewer, John Brunero, John Hyman, Kim Frost and Thodoris Dimitrakos.

${ }^{3}$ For a recent defense of a narrow-scope interpretation, see Schroeder $(2004,2007,2009)$.
} 
subject to instrumental norms in considering whether to intend the means to one's end or revise the intention for one's end given rational relations - the relations among one's attitudes; and to telic norms in considering whether to intend an end or the means to one's end given reasons relations - the relations between facts in the world and one's attitudes. ${ }^{4}$

But despite its dominance, the foundations of the attitudinal picture are shaky. Its proponents are either led to the conclusion that instrumental rationality is mythical ${ }^{5}$ or keep adding epicycles to the narrow- and wide-scope interpretations in order to counter a growing number of objections. ${ }^{6}$ In either case it seems difficult to do justice to the following three intuitions: On the first intuition, not taking the means to one's end is criticizable, even if doing so would be impermissible from the perspective of telic normativity. For instance, we may think that something has gone wrong with the capitalist who is not exploiting the workers' labor, even if we think that one ought not exploit the labor of others. On the second intuition, instrumental norms may not constitute reasons for an action that is impermissible from the perspective of telic normativity. For instance, if we think that one ought not employ children's labor, we may not think that the capitalist has reason to employ children's labor even if children's labor is cheap and employing cheap labor is the necessary means of making profit. And on the third intuition, instrumental and telic norms are both practical.

${ }^{4}$ For defenses of the wide-scope interpretation, see Broome (1999, 2001, 2004, 2005, 2007); Dancy (2000); Wallace (2001); and Brunero (2007, 2010, 2012).

${ }^{5}$ Notably Kolodny (2005, 2007a, 2007b, 2008a, 2008b) and Raz (2003, 2005a, 2005b).

${ }^{6}$ For some of these objections, see Setiya (2005, 2007), Bedke (2009), etc. For a revised narrow-scope account, see Shroeder (2009, 2011); and for a revised wide-scope account, see Way (2010, 2011).

Manuscrito - Rev. Int. Fil. Campinas, v. 41, n. 4, pp. 349-388, Oct-Dec. 2018. 
A different theory of intention, tracing back to Anscombe, ${ }^{7}$ has recently given rise to an alternative constitutivist picture of instrumental normativity. On this theory, to understand intention we should turn our attention away from propositional attitudes and focus on the structure of intentional action. This is the structure of a means-end unity (e.g., studying in order to get good grades), that is chosen for a value it purportedly embodies (studying in order to get good grades as the embodiment of honor). On the emerging constitutivist picture, the agent is subject to instrumental norms in the constitution of her activity as an intentional action (studying in order to get good grades), and to telic norms in the constitution of a consideration for an activity as the ground of her choice of a means-end unity or else as the value that her intentional action embodies (studying in order to get good grades for the sake of honor).

Constitutivism comes in two varieties so far. On Korsgaard's Kantian variant 8 action constituting instrumental norms draw their normativity from the normativity of choice governing telic norms (of the categorical imperative, in particular). But this account explains instrumental normativity at the cost of abandoning the first intuition above, on which not taking the means to one's end is criticizable, even if doing so would be impermissible from the perspective of telic normativity. To do justice to this intuition, neo-Anscombean ${ }^{9}$ constitutivists propose that we should seek the source of the action

\footnotetext{
7 Anscombe (1957).

${ }^{8}$ Korsgaard $(1997,2008)$.

9 Valaris (2014, 2015). Vogler (2002). Arguably, also, Thompson (2008). I call these accounts "neo-Anscombean," to register my doubt as to whether Anscombe herself embraces their fundamental commitment. I will not go into issues of exegesis in this paper, but for a similar doubt see Wiseman (2016).
} 
constitutive instrumental normativity in the metaphysics of intentional action. And, in particular, in the nature of intentional action as a finite process: a course of events whose proper unfolding will, if all goes well, reach its final or completing stage.

In this paper I develop an argument against the neoAnscombean variant of constitutivism and sketch the outline of an alternative Murdochian constitutivist account. Neo-Anscombean constitutivism is worth examining, for it gives expression to a widely shared assumption concerning the normative implications of the infinite (or finite) character of some of our actions. An assumption there is reason to reconsider; or so I shall argue. The argument proceeds in the following manner: In the first section, after a short introduction to constitutivism, I examine the neoAnscombean idea that the instrumental principle applies to finite activities only (activities, such as gathering my tools to fix my bike, whose end is finite; i.e. exhausted when achieved) and not to infinite activities (activities such as biking for the sake of health, whose end is infinite; i.e. not exhausted when achieved). I trace this idea to the widely shared assumption (the Neo-Anscombean Assumption) that in the case of infinite activities, the activity of pursuing an end manifests this end and so may not progressively realize this end. ${ }^{10}$ In the second section, I present cases in which taking the means to one's end appears to be both what manifests an infinite end and what progressively realizes this end. In the third section, I argue that to save the phenomena in these cases, we need to conceive of telic norms as themselves growing in the unfolding of the means-end unities that embody them. In the fourth section, I explain the possibility of growing telic norms by reverting to what I take to be Murdoch's account of the practicable good as the

${ }^{10}$ For different expressions of this assumption see McDowell (32-33), Brewer (2012: 129), Rödl (2007: 34-38), etc.. 
good whose nature is determined by the activity of pursing it. In the final section, I explain how this account of telic norms makes room for an alternative constitutivist variant of instrumental normativity which does justice to the three intuitions above. The idea is, roughly, that the instrumental principle may apply to both finite and infinite activities, because it is the normative principle which constitutes a means-end unity as perfectible activity. And an activity is perfectible either when the telic norm embodied in it may be full determined by the activity of pursuing a finite end (such as walking to the store) or when telic norm embodied in it may be progressively determined by the activity of pursuing an infinite end (such as sharing my life with you). This account of instrumental normativity, I finally show, does not reduce instrumental to telic normativity.

\section{THE NeO-ANSCOMBEAN VARIANT OF ConstitutivisM}

\subsection{THE CONSTITUTIVIST PICTURE OF INSTRUMENTAL NORMATIVITY}

The constitutivist picture of instrumental normativity entails commitment to two claims: 1) that intention is a thing constituted by normative standards, and 2) that the normative standard which constitutes intention is the requirement to take the means to one's ends.

Roughly speaking, the idea of the normative constitution of a thing is the idea that some of the norms under which an object falls are given by the object's function. ${ }^{11}$ To use Korsgaard's example, the notions that

\footnotetext{
${ }^{11}$ Korsgaard relies on this idea in order to develop her account of agency as self-constitution (2008). Thompson also relies on this idea in order to develop his account of life (2008).
} 
the walls of the house should be joined in the corners, that the insulation should go in the walls, etc., are all norms that follow from a house's function (to provide habitable shelter), in the sense that meeting these norms, at least to some extent, enables the house to serve its function well and so be a house. Thus certain norms under which an object falls are normative constitutive standards: standards that determine what it is to be the object by determining what it is to do well what the object does. On this idea, the issue of the justification of constitutive normative standards does not arise in the same way that it arises for other norms. Normative constitutive standards apply to an object necessarily, because they determine what an object is or does. And so the justification of their applicability lies in an account of what the object itself is or does and of how these normative standards enable the object to do well what it does-i.e., to serve its function well. By contrast, noninstrumental norms apply to an object in virtue of further facts about it, so that the justification of these norms must refer to these further facts. ${ }^{12}$

On the constitutivist picture, which is the topic of this paper, the requirement to take the means to one's end normatively constitutes intentional action as a means-end unity. ${ }^{13}$ And the requirements concerning what one ought to do (telic requirements) constitute the grounds for the

12 The very idea of the normative constitution of a thing faces many problems. See Lindeman (unpublished), Railton (1997) and Clark (2001). But these are problems faced by any account of the normative constitution of intentional action, and so I shall set them aside in this paper.

13 This picture of intentional action may be traced back to Anscombe's account of intentional action as that happening in the world whose structure is the instrumental structure of the spontaneous (nonobservational) knowledge of what one is doing: "I'm doing $\mathrm{z}$ because I'm doing $\mathrm{y}$, where $\mathrm{z}$ is the means to my end and y is my end." Anscombe (1957). 
choice of a means-end unity; i.e. the value one's intentional action embodies. Thus we have, on this picture, two kinds of constitutive principle:

Instrumental Principle: The instrumental requirement is the normative standard or principle which constitutes an activity as one's intentional action; i.e. a means-end unity.

For instance, the requirement to take the means to one's ends is the standard which may constitute solving a geometry problem as one's intentional action of studying in order to get good grades.

Telic Principle: A telic requirement is the normative standard or principle which constitutes a consideration in favor of an activity as what grounds the agent's choice of a means-end unity; i.e. as the value the agent's intentional action embodies.

For instance, the requirement of honor may constitute the consideration of shame in perfoming badly at school as the ground of choosing to study in order to get good grades; i.e. as the value embodied in one's intentional action.

This picture of instrumental normativity has considerable advantages over the attitudinal picture. First of all, it provides a simple explanation of the second intuition about instrumental normativity: That instrumental norms may not constitute reasons for an action that is impermissible from the perspective of telic normativity. When an agent's behavior is criticizable from the perspective of instrumental normativity it is not criticizable in light of what reasons prescribe but in light of what is an intention; and this is possible because intention is a thing normatively 
constituted. Secondly, instrumental norms are practical even if they do not guide action by providing reasons for intending. They are practical in that they guide the agent in the constitution of her intention. Moreover, if this alternative picture is granted, Kolodny's skeptical worry ${ }^{14}$ loses part of its strength. If the instrumental requirement is internal to the constitution of intention, then the issue of its justification does not arise in the same way that it arises for other requirements. To justify the instrumental requirement, we need only refer to what intention is and how the instrumental requirement allows intention to serve its function. ${ }^{15}$

But now the question arises: What is the function that the instrumental requirement allows intention to serve? Depending on the answer, we get a Kantian or a neoAnscombean variety of constitutivism. On the Kantian variety, the function of intention is to enable agents to successfully meet telic principles (ultimately, the categorical imperative). ${ }^{16}$ And on the neo-Anscombean variety, the function of intention is to enable agents to get things done. ${ }^{17}$ The Kantian account is more subtle than this, but in what follows I will set it aside, for it does not aspire to do justice to the intuition that instrumental norms are applicable even when there are no telic norms which would be met if one took the means to one's end. In the next two sub-sections of this section, I examine the neoAnscombean variant of constitutivism and argue that it is

\footnotetext{
14 The worry is that we cannot provide a reason for adhering to the instrumental requirement (Kolodny 2005).

15 The skeptic might respond that Kolodny's worry is thus merely renewed into the question: Why intend at all? But the worry is premature, for the ambition of the constitutivist discussion is to locate the answer to this question in the true account of the constitution of intention.

16 See, for instance, Korsgaard (2008: 68-69).

17 Valaris (2014).
} 
too restrictive. This argument will pave the way for the Murdochian constitutivist account I will develop in the final section of the paper.

\subsection{NEO-ANSCOMBEAN CONSTITUTIVISM}

On the neo-Anscombean accounts, intentional action is by nature the sort of thing that tends to get done. ${ }^{18}$ If I am reading papers on instrumental normativity, keeping notes, etc., without giving any thought to whether I will ever have written a paper, then I am under no circumstances writing a paper intentionally. As Valaris puts it in his defense of the neoAnscombean account, this is not an empirical generalization about agents but "a metaphysical claim, about what it is to act intentionally." 19 But if to be doing A intentionally just is to be committed to getting A done, and if $\mathrm{M}$ is the necessary means to doing $\mathrm{A}$, then to fail to do $\mathrm{M}$ is to fail to get A done and so to fail by the lights of what counts as exercising well one's capacity to act intentionally or intend. And thus it follows from the function of intention (enabling the agent to get things done) that one ought to take the means to one's end. ${ }^{20}$

\footnotetext{
18 Valaris (2014: 450).

${ }_{19}$ Valaris (2014: 457)

20 This account may seem counterintuitive for two reasons: 1) It draws on facts about intentional action and not intention, and 2) it refers to facts about what the necessary means to an end are and not what the agent takes the necessary means to her end to be. In response to (1), a neo-Anscombean may suggest that intending is, as Valaris puts it, "the servant of doing" (Valaris, 2014: 454) and so what holds of intentional action will also hold of intention. And in response to (2), she may simply bite the bullet. In what follows I will assume that a neo-Anscombean account may overcome both of these difficulties and argue that it fails for a different reason.
} 
But this is not the end of the story. For one may raise the question Why get things done at all?, to which one may be inclined to revert either to the skeptical answer (there is no reason) or to the Kantian answer (the reason is given by a telic principle). On the neo-Anscombean account, the answer lies in the explanation of the metaphysics of intentional action as a process. ${ }^{21}$ On this explanation, the relation between one's doing A and one's having done A is an instance of a more general relation between a process (represented by a progressive sentence of the form " $\mathrm{a}$ is Ving") and its completion (represented by a perfective sentence of the form "a has V-ed"). ${ }^{22}$ This relation is such that any course of events which involves a $\mathrm{V}$-ing but not having V-ed is a course of events of a failed V-ing - a course of events in which something has gone wrong. On this picture, then, the failure to follow the instrumental requirement is an instance of a process' failure to reach completion. ${ }^{23}$ And the intention constitutive requirement to get things done owes its normative force to the nature of intentional action as a process.

The cases that set the tone for this account of intentional action are taken from biology: ${ }^{24}$ a course of events of a fruit's ripening which does not issue in the fruit's having ripened is a course of events in which

21 Thompson (2008).

22 This move relies on the aspectual distinction between modes of predication (perfective and imperfective) that Comrie first introduced and Thompson put back into circulation. See Comrie (1976) and Thompson (2008: 123-130).

${ }^{23}$ A neo-Anscombean need not deny that the efficaciousness of intention may involve notions of responsibility, and so telic norms (Valaris 2014: 453-454). But she may suggest that the way intention's efficaciousness is tied to telic norms is intention's manner of being a process.

24 Thompson's theory of intentional action is embedded in a philosophical account of life (Thompson 2008: 25-85). 
something has gone wrong. For the natural resting point of the fruit's ripening is the state of affairs in which it will have ripened. But that a fruit will have ripened means that it will no longer be ripening. Thus, in a way, the fruit's ripening aims at its own extinction. For, in general, the moment a process is completed is the moment that process is no more. ${ }^{25}$ Similarly, the resting point of walking to the store is the state of affairs in which the agent will have walked to the store. Intentional action is, on this picture, constituted by the instrumental requirement, because intentional action is the kind of thing that aims at its own extinction by aiming towards a state of affairs in which it will have been completed. I need to be taking the means to my end, because I am engaged in an activity whose nature is such that it will not unfold properly unless it reaches its final or completing stage. This move enables neo-Anscombeans to explain instrumental normativity without reducing it to telic normativity, as Korsgaard does, and without referring to reasons in a way that would rekindle Kolodny's skeptical worry. For, as Valaris says, “... even if one is pursuing a project one knows that one ought not to pursue, one is still engaged in a course of action that will result in one's having completed that project, unless something goes wrong." 26

\subsection{THE NEO-ANSCOMBEAN ASSUMPTION}

A natural reaction against this neo-Anscombean account arises from consideration of intentional actions that do not aim at their own extinction. For example, in the case of biking in order to be healthy, health is an end that is not exhausted when achieved (an infinite end): Even when I am

25 This account of intentional action is modelled on Aristotle's account of poiesis. See Nicomachean Ethics 1140b6-7.

26 Valaris (2014: 457).

Manuscrito - Rev. Int. Fil. Campinas, v. 41, n. 4, pp. 349-388, Oct-Dec. 2018. 
successfully biking in order to be healthy and I am achieving my end, I am not thereby exhausting it. If I truly care about being healthy I will have to bike today, but also eat a good breakfast tomorrow, avoid stressful situations, and so on and so forth. But if neo-Anscombeans are right in their insistence that intentional action is finite activity which aims at its own extinction in the sense specified above, biking in order to be healthy will not count as an intentional action. But then what else might it be?

The neo-Anscombean will respond that an activity may relate to an infinite end (an end that may not be exhausted even when achieved) as a means-end unity relates to a telic principle (a principle which constitutes a consideration for an activity as the value embodied in one's intentional action) and not as the means to one's end relate to that end. ${ }^{27}$ On this picture, the instrumental principle constitutes intentional action as a finite activity (a unity of means with an end that is exhausted when achieved) and these finite activities may themselves relate to infinite ends as their manifestations and not as the instrumental means to them. On this view of the matter, to say "I bike in order to be healthy" is to say something like "I'm taking a ten minute break from work in order to bike and I thereby take it that to do so is to be healthy." The assumption implicit in this response is that all infinite ends are what Thompson calls habituals: principles which are not directed at particular activities but which are general both in the sense that an infinite number of activities falls under them and in the sense

27 A corollary of this is that there are no basic or atomic actions. See, for instance, Thompson (2008: 107). Vogler seems to admit the possibility of unities of atomic actions (means) directly with infinite ends. But she argues that the unity of means with finite ends is the paradigmatic case of intentional action, without which there could be no other. See Vogler (2002: 130-132). 
that reference to a particular time is not part of their essence. ${ }^{28}$ For instance, of the principle of fidelity, Thompson says that it "is essentially one and the same, unchanged, unexhausted, and not merely similar, through a potentially unlimited series of individual acts of fidelity. ... [P] ractices and dispositions do not come to a limit in any action or event or in any totality of actions and events that could thereby be said to satisfy, execute or complete them; they can only be said to be manifested, instanced or exhibited in any such thing." 29

But, even if we accept that all unities of activities with infinite ends are in reality unities of finite activities (meansend unities) with infinite ends, the natural reaction above may resurface: why deny that some of these finite activities (means-end unities) may relate to infinite ends as instrumental means to ends? The reason for this denial lies in an assumption which reaches beyond the confines of the neo-Anscombean account of intentional action. I shall nevertheless call this The Neo-Anscombean Assumption.

\section{Neo-Anscombean Assumption: If an activity manifests an infinite end, then this activity cannot progressively diminish the distance between the agent and this end in the way that instrumental means to ends do.}

For instance, the activity of gathering one's tools is instrumentally related to fixing the bike, because gathering one's tools is one of the things that progressively diminish the distance between oneself and the end of fixing the bike. By contrast, biking cannot, on this view, relate to health instrumentally, because if it such as to manifest health it will

\footnotetext{
28 See Thompson (2008: 158-159), but also Rödl (2007: 32-33) and Vogler (2002: 105-107).

29 Thompson (2008: 158-159).
} 
not be able to progressively diminish the distance between oneself and health. The thought is this: if to bike just is to be healthy when biking is successful, then one is either being healthy in biking or not. For one is either successfully biking or not. But if there is no progressively diminishable distance between me and my end, then the instrumental requirement cannot govern the unfolding of an activity which manifests an infinite end. For what this requirement requires (closing the gap between me and my end) is always already done in the successful activity.

Implicit in this thought and thus in The NeoAnscombean Assumption is what I shall call the The Determinateness Thesis.

Determinateness Thesis: if an activity manifests an infinite end, the end must be fully determinate (albeit inexhaustible) in its manifestation. ${ }^{30}$

To back the Determinateness Thesis the neoAnscombeans revert to the Aristotelian dictum that infinite activities (activities which have no terminating point $(\pi \dot{\varepsilon} \varrho a \varsigma))$ are activities which include their own end in the sense that seeing includes its own end; for at once one is seeing and has seen. ${ }^{31}$ If one is biking for the sake of health and biking is a manifestation of health, in biking and so in being healthy one has already biked and so one has already achieved health, in the way that, in seeing, one has already seen. The thought here seems to be that if the perfection of finite activities lies in having completed, executed or satisfied an end (e.g. having built in the case of building), then the perfection of an infinite activity (having seen) lies

\footnotetext{
${ }^{30}$ Vogler expresses this thesis when she says that "without some determinate end in view, there is no reason to do anything" (Vogler, 2002: 49).

31 See Aristotle, Metaphysics 1048b18 - 1048b35.
} 
in the activity of pursuing an end (seeing) and not in having completed, executed or satisfied an end. The activity of pursuing an infinite end and the perfection of this activity are, on this line of reasoning, one and the same thing. ${ }^{32}$ But the conclusion that neo-Anscombeans draw from this thought is this: that if the activity of pursuing an infinite end and its perfection are to be one, then the end must always be fully determinate (and in this sense perfect) in every instance of this activity. In other words, that the Determinateness Thesis holds.

But this conclusion is not warranted by the Aristotelian equation of the activity of pursuing an infinite end with the perfection of this activity. As always in these cases, what matters is the order in which we read the equation. If we read the equation from the activity of pursuing an infinite end to the perfection of this activity, then the Determinateness Thesis might seem to follow. But if we read the equation from the perfection of the activity of pursuing an infinite end to the activity of pursuing an infinite end, a different possibility opens up. This is the possibility of conceiving of the perfection of the activity of pursuing an infinite end as an activity. But if the perfection of the activity of pursuing an infinite end is an activity, then we start to loose our grip on what it would mean to say that this end is always fully determinate in the activity of pursuing it. ${ }^{33}$ On the contrary; the more we come to terms with the idea that the perfection of the activity of pursuing an infinite end is an activity, the more we see that the activity of pursuing an infinite end is the activity of determining this end.

\footnotetext{
32 For this interpretation see, for instance, Kosman (2013: 44).

${ }^{33}$ For an extended argument against the assumption that one's ends in intending must be fully determinate see Brewer (2012).
} 
In what follows I will try to give substance to this conception of the perfection of the activity of pursuing an infinite end as itself an activity. Doing so will allow me, in the final section, to sketch a Murdochian constitutivist account of the instrumental principle.

\section{The Phenomena: Instrumental Unities of MEANS WITH INFINITE ENDS}

To appreciate that the Neo-Anscombean Assumption is false and that there exist cases in which taking the means to one's end may both manifest one's end and progressively diminish the distance between oneself and one's end, consider the following expressions of intention: "I intend to act in pursuit of the end of sharing my life with you", "I intend to act in pursuit of the end of corrupting the youth by teaching moral philosophy", "I intend to act in pursuit of the end of defending the rights of the oppressed", "I intend to act in pursuit of the end of participating in public life", "I intend to act in pursuit of the end of becoming brave", etc. In all these cases the following claims seem true: a) the agent intends to act so as to pursue an infinite end-one which may not be exhausted when achieved, b) when successful, the agent's activity manifests, instances or exhibits an infinite end, and finally c) the agent's end is not fully determinate in every instance of the activity of pursuing this end. For in all these cases it seems possible to progressively diminish the distance between oneself and one's end in the activity of pursuing one's end. For it is conceivable that in different moments or stages of the activity of manifesting one's end one may find oneself closer to or further away from one's end. But if it makes sense to speak of varying degrees of distance between oneself and these infinite ends, then the instrumental 
requirement could apply even in these cases. And the NeoAnscombean Assumption would be false.

At this point a neo-Anscombean may object that at least some of the ends mentioned above are finite. ${ }^{34}$ For instance, one might think that intending to share my life with you is the kind of thing which is exhausted at death. The problem with this response is thats death is not a thing one may do to complete, execute or satisfy what one aims at, as is, for instance, entering the store when walking to the store. What terminates the end of sharing my life with you in this case is not something I do, but something that merely happens. And so "till death do us part" in a marriage vow is not analogous to "till I have entered the store" in the case of walking to the store. Therefore, the possibility of the former utterance does not render the activity it represents finite, in the way that the possibility of the latter utterance does. When I intend to act in pursuit of the end of sharing my life with you, what I am thereby aiming at is not the extinction of the activity by a certain time-frame, but, on the contrary, the activity itself. Thus, even if we manage to envision a state of affairs in which it would no longer be possible to have this end, this would not be sufficient to render the end finite.

To see this even more clearly consider the intention to fight for the rights of the oppressed. A neo-Anscombean may suggest that this intention may be exhausted by the extinction of oppression. But if by the extinction of oppression we refer to something like a catastrophe that finishes off the human species, then my response is the same as above: This extinction is not what the agent herself would be doing, and so is not equivalent to entering the store in the case of the finite end of walking to the store. If, on the other hand, by the extinction of oppression we refer to something the agent might be doing, then this specification

34 Thompson seems to take this line (2008: 159). 
(extinguish oppression) is not a description of what would count as completing the end of fighting for the rights of the oppressed, but as a mere re-description of the end. One may say "I intend to fight for the rights of the oppressed" or one may say "I intend to extinguish oppression". But neither of these two utterances is any more of a determination of the end than the other. A determination of the end in these cases would, intuitively speaking, be a thing the agent might do in pursuit of these ends in particular circumstances such that it would count as manifesting these ends. ${ }^{35}$

Alternatively, a neo-Anscombean might suggest that at least in some of these cases the ends are Thompsonian habituals: practices which are general both in the sense that an infinite number of activities falls under them and in the sense that they are the same through a potentially unlimited series of individual acts. For instance, corrupting the youth or defending the rights of the oppressed might be seen as ends that remain the same throughout a potentially unlimited series of individual acts that manifest them. As we saw in section 2.3, this is possible if the Determinateness Thesis holds; i.e. if these ends are fully determinate in every instance of the activity of pursuing them. But if the Determinateness Thesis holds, then these ends must be determined independently of the activity of pursuing them. (After all, not all instances of the activity of pursuing them are the same: One fights for the rights of the oppressed now by marching in the streets and then by teaching philosophy. Thus if these ends remain the same throughout these acts that manifest them, then they must be determined independently of these acts.) And if the determination of one's ends (figuring out what here and now constitutes the pursuit of these ends) lies outside the

35 For this conception of the determination of an infinite end see McDowell (1978, 1993) and Wiggins (1987). 
activity of pursuing them, then this determination must be the result of a theoretical inquiry about what means manifest what ends. In which case the activity of pursuing an end would be practical in the sense that it is the mere execution of a theoretical determination of the sort: This act here and now constitutes the pursuit of this end. ${ }^{36}$ But this move faces the following problems.

Despite the fact that there is not much left that deserves to be called "Anscombean" in such an explanation, ${ }^{37}$ this move presents some of our lives' most extended, unified and practically demanding projects as a mere aggregate of individual acts that are unified by the fact that they happen to manifest the same end. In doing so it reduces the richness and diversity of the skills involved in the activity of pursuing of an infinite end such as fighting for the rights of the oppressed to the simplicity and the singularity of the skills involved in the activity of executing a plan. ${ }^{38}$ But as Brewer nicely puts it, "the work of proper deliberation is not the work of an accountant." 39 From reflecting on the narrowness of this conception of the activity of pursuing infinite ends, Brewer concludes that in these cases the activities of pursuing an end cannot bear an "instrumental relation to the telos in whose light, they appear choiceworthy." 40 For Brewer, as well, assumes that an

${ }^{36}$ For an extended argument against this conception of practical reasoning and action see Brewer (2011: 12-68). Brewer calls this “action as a species of production" (2012: 12).

37 Anscombe famously rejects speculative accounts of practical reasoning and practical knowledge. See Anscombe (1957: \$3246).

${ }^{38}$ This is what Brewer calls "action as a species of production." Brewer (2012: 12).

${ }^{39}$ Brewer (2012: 103).

${ }^{40}$ Brewer (2012: 129). 
activity may bear an instrumental relation to its end only if the end of an activity is "some conceptually separate state of affairs that the activity promises to produce." ${ }^{41}$ In the next section, though, I will argue that we do not have to assume this. We may in fact make sense of the possibility of an activity of pursuing an infinite end which both manifests this end and progressively diminishes the distance between oneself and this end. And so, we may make sense of the possibility of at least some instrumental unities of activities with infinite ends.

\section{Doing Justice to the Phenomena: Growing TELIC PRINCIPLES}

To see that it makes sense to speak of the above cases as cases of instrumental unities of means with infinite ends, it will help to consider some examples in more detail. In this section I will present two examples and suggest a way in which we can do justice to the phenomena of instrumental unities of means with infinite ends:

1. After years of promiscuity, Sally meets Tom. Sally eventually decides to act in pursuit of the end of sharing her life with Tom, for the sake of companionship. Now say that Sally has a hard time sticking to one sexual partner at first, but is now successfully sharing her life with Tom by sticking to Tom as her only sexual partner. But in doing so, she is not inexhaustibly realizing a fully determinate end. For even if initially it may be the case that to share her life with Tom is to exclude other sexual partners, if excluding other sexual partners enables her to develop an intimate erotic

${ }^{41}$ Brewer (2012: 129). 
relationship with Tom, it may turn out that to share her life with Tom grows to be what lies in bringing this intimacy to other aspects of her relationship with Tom. And if bringing this intimacy to other aspects of her relationship with Tom allows her to expand her sense of herself, it may turn out that sharing her life with Tom grows to be what lies in embracing and inhabiting the expanded sense of herself, etc.

2. Mark is taking part in the rallies of the Black Lives Matter movement in his town. He has decided to so in order to fight for the rights of the oppressed, for the sake of justice. And now let's say that Mark is successfully fighting for the rights of the oppressed in rallying. But in doing so Mark is not thereby inexhaustibly realizing a fully determinate end. For even if initially it may be the case that to fight for the rights of the oppressed is to rally, if rallying grows inefficient it may turn out that fighting for the rights of the oppressed grows to be what lies in organizing, and if organizing develops into a mere bureaucratic machine it may turn out that fighting for the rights of the oppressed grows to be what lies in solidarity across difference, and if solidarity across difference becomes mere charity, it may turn out that fighting for the rights of the oppressed grows to be what lies in class war, etc.

And now consider these cases together. A neoAnscombean will think that as rallying becomes ineffective, the end remains one and the same while its manifestations change (in the way that pleasure is one and the same end manifested both in eating sweets and in reading Murdoch). And a skeptic will think that the end merely changes from being the kind of thing manifested in rallying to being the 
kind of thing manifested in organizing. In other words, one may think either that these ends are Thompsonian habituals or that they are only nominally the same ends. But there is a way to undercut the dilemma between Thompsonianism and thorough-going skepticism. For there is an alternative: As the instrumental facts (facts about what the means to one's infinite ends are) change, the distance between oneself and the ends varies, for the principles that are realized in each successive manifestation of the ends themselves grow with the unfolding of the activity they govern.

Take Sally's intention to act in pursuit of sharing her life with Tom for the sake of companionship. As Sally's activity (taking the means to her end) unfolds, companionship itself deepens. Where before it involved letting no other sexual partner stand in the way between her and Tom, now companionship involves being lovers for each other in the way that no others are. But this is not a claim about Sally's psychology or thought and how it relates to an an already determinate, and thus independently determinable conception of companionship. Rather, this is a claim about the principle itself. One might say that whereas, before, in taking the means to her end companionship was determined negatively as the exclusion of the other, now it is determined positively as the recognition of the concrete reality of the other. Similarly, as Mark's activity unfolds from protesting to organizing, the principle of justice itself grows. One might say that whereas before the principle of justice was determined negatively as protesting the ills of a corrupt political society, now it is determined positively as coming together with others to build equal membership in new political societies. In both cases, where at first the principle at issue involves consciousness of what threatens its unity, it then grows to involve consciousness of what constitutes its unity. This, I think, is what Murdoch means when she says, "As we deepen our notions of the virtues, 
we introduce relationship and hierarchy. ... We come to distinguish a self-assertive ferocity from the kind of courage which would enable a man coolly to choose the labor camp rather than the easy compromise with the tyrant." 42

But if it makes sense to speak of infinite ends which may be achieved to a lesser or greater extent in the unfolding of the activities that manifest them, then it makes sense to say that these activities may in fact progressively diminish the distance between oneself and one's end in the way that instrumental means do. And so we may think that the instrumental requirement may constitute intentional action both as a unity of means with finite ends and as a unity of means with infinite ends. Thus, we may give the following schematic account of instrumental normativity in the case of unities of means with infinite ends: if to intend to do A in these cases is to be committed to progressively determining a telic principle $\mathrm{P}$, and if $\mathrm{M}$ is the necessary means to $\mathrm{A}$, than to fail to do $\mathrm{M}$ is to fail to progressively determine $\mathrm{P}$, and so to fail by the standards of what in these cases counts as exercising well one's capacity to intend. But this account of unities of activities with infinite ends makes sense only if we make room for the idea that telic principles may themselves grow. In the next section, I sketch a way of making this room.

\section{A Murdochian ACCOUNT OF Telic Principles}

Initially it seems difficult to understand how a telic principles which is embodied in an infinite number of individual actions (means-end unities) may itself grow. As we saw in section three, it seems that if telic principles are to govern an infinite number of means-end unities, then the Determinateness Thesis must hold: these principles must

${ }^{42}$ Murdoch (1971: 93).

Manuscrito - Rev. Int. Fil. Campinas, v. 41, n. 4, pp. 349-388, Oct-Dec. 2018. 
be fully determinate. And if these principles are fully determinate even though they are embodied in an infinite number of actions, they must be determinable independently of the activity that embodies them. But there is an alternative: the sense in which telic principles are infinite (inexhaustible even when realized) is not the technical sense in which they may be embodied by an infinity of individual actions. Telic principles are infinite in the radical sense that we may never exhaust them because they may not be determined independently of the unfolding of the activities in which they are embodied. On this alternative, the infinity of telic principles implies that the Determinateness Thesis is false. But if the Determinateness Thesis is false, then what I shall call Murdoch's Insight must be true.

Murdoch's Insight: if telic principles may not be determined independently of the activity that embodies them, they must be such as to grow in the unfolding of the activity that embodies them. ${ }^{43}$

To neglect this alternative is to assume that telic principles are timeless and unchanged by the knowledge and the reality that the activity in which they are realized gives rise to. A neo-Anscombean may object that even Thompsonian habituals may change with time. Thompson notes, in a footnote to Life and Action, that the generality of his habituals "should not be understood to mean that an agent cannot lose a disposition

${ }^{43}$ This insight is, I think, what Murdoch presupposes when she says of moral (telic) terms that they "must be treated as concrete universals" (1971: 29). This is the central idea of Murdoch's account of the practicable good in her Sovereignty of the Good (of telic principles, in my terminology) and the reason why Murdoch uses the concept of perfection to explicate the nature of this good. 
or that a practice cannot die out; it is just that this cannot be the work of the disposition or practice itself'. ${ }^{44}$ What justice requires of an agent in a given society may be different from what it requires of agents in other societies. But on the Thompsonian account, changes in the articulation of these habituals are not the work of these habituals themselves. In my terminology, on the Thompsonian account of change in the articulation of infinite ends, this change cannot be the work of the ends themselves. Thus, even though these principles may change, change is not part of their essence. Therefore, even this refined neo-Anscombeanism assumes that the infinity of telic principles must imply that in their essence they are timeless.

But it is not clear why we have to accept this. We may instead think that even though telic principles are infinite, they are essentially historical-that is, they grow in the unfolding of the activity they govern. Murdoch's Insight gives us a deeper sense in which telic principles are practical principles; or, in a Murdochian cum Aristotelian terminology, the sense in which the good is the practicable good. ${ }^{45}$ If Mudorch's Insight is false, then the good's practical character must be restricted to a sort of efficacy: the efficacy either of an essentially timeless (Platonic) idea of the good, or of an essentially timeless (Thompsonian) practice of the good, or of an essentially timeless (Kantian) law, etc. ${ }^{46}$ But if Murdoch's Insight is correct, if the

\footnotetext{
44 Thompson (2008: 159).

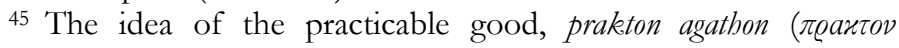
$\dot{\alpha} \gamma a \theta \dot{o} v)$, is prominent in Aristotle's works. See, for instance, De Anima 433a27-30 and 433b22-30, Eudemian Ethics 1.8 1218b4-6, Nicomachean Ethics 1097a1, Nicomachean Ethics 1141b9-14, etc.

46 Even though Murdoch conceives of her account of the practicable good as Platonic, she vehemently rejects the picture of agency as the exercise of a pure will and conceives of it 
principles of the good (telic principles, in my terminology) themselves grow in the unfolding of the activity they govern, then to say that the good is practicable would be to say that its very essence arises out of the unfolding of the historically determined, concrete human activity of realizing it. The practicable good on Murdoch's Insight is then the good whose nature is determined in the unfolding of the activity of pursuing it. ${ }^{47}$ If we embrace Murdoch's Insight, we come to see that telic principles are practical both in the sense that they guide the activity of taking the means to an end and in the sense that their nature is determined by the unfolding of this activity. 48

To neglect this possibility is to neglect the possibility that the practicable good may be practical in its essence and not merely in its effect. And this is to neglect the possibility of intentional action as an activity with the ability to not merely complete/execute/satisfy or realize/specify/instantiate an already determinate good, but to progressively determine its own good. Intentional action conceived as an activity with the ability to progressively determine its own good would be, in Murdoch's terminology, an activity with the ability to

"essentially something progressive, something infinitely perfectible" (1971: 23); that is, historical (1971: 25).

47 And this explains Murdoch's insistent rejection of accounts on which agency is "thin as a needle" and "appears in the quick flash of the choosing will" (1971: 52).

48 In light of this double function we might, together with Brewer, call these activities "dialectical" (Brewer 2012). I should note here though that Brewer does not draw the metaphysical conclusion that the unfolding of the activity of pursuing an infinite end determines the nature of these principles. What Brewer says is that each successive engagement with an activity yields a further stretch of understanding of the good (see for instance Brewer 2012: 36). 
perfect itself. ${ }^{49}$ This is what Murdoch means when she says, "Moral tasks are endless not only because 'within', as it were, a given concept our efforts are imperfect, but also because as we move and as we look our concepts themselves are changing." 50 Thus, to think that the practicable good itself may not grow because it is fully determinate, (to adhere, that is, to the Determinateness Thesis) is to neglect the possibility that the principles of the practicable good are essentially historical realities whose fate is the fate of the activities they hold together. As Murdoch puts it, "We ordinarily conceive of and apprehend goodness in terms of virtues which belong to a continuous fabric of being. And it is just the historical, individual nature of the virtues as actually exemplified which makes it difficult to learn goodness from another person." 51

A natural objection to this view is that if telic principles may themselves grow in the activities they govern, then it will be difficult to see how these growing principles may give unity to the unfolding of the activities they govern. This objection sounds urgent on the assumption that something essentially changing may not give unity to the unfolding of an activity. But the telic principles are, on this view, not merely changing. They are growing. And now one will object: how is it possible for telic principles themselves to grow if there is no such thing as a pre-determined stage they can reach when fully grown? To counter this objection we may, following Murdoch, conceive of telic principles as

\footnotetext{
${ }^{49}$ Of perfection Murdoch says that it is that in whose light "we come to see that A, which superficially resembles $B$, is really better than B. And this can occur, indeed must occur, without our having the sovereign idea in any sense "taped". In fact it is in its nature that we cannot get is taped" (1971: 60-61).

${ }^{50}$ Murdoch (1971: 27).

51 Murdoch (1971: 29).
}

Manuscrito - Rev. Int. Fil. Campinas, v. 41, n. 4, pp. 349-388, Oct-Dec. 2018. 
having an ideal limit ${ }^{52}$-a limit which necessarily transcends all of our activities of reaching it, but a limit which we nevertheless may count ourselves as getting closer to or further away from. And even though we may not know how these principles will be determined at the ideal limit, we could, for instance, venture the hypothesis, together with Murdoch, ${ }^{53}$ that the determination of these principles at the ideal limit will give us access to the individual reality of the other-whatever this other may be turn out to be. ${ }^{54}$ We could, for instance, think of the activities I considered in the previous section as held together by principles capable of growing towards the ideal limit of the infinite and inexhaustible reality of the other (the other qua lover and the other qua equal in the example of sharing one's life with someone and the example of fighting for the rights of the oppressed).

One may, finally, object that even if we manage to ground a notion of the ideal limit of telic principles in a full account of telic principles, this notion is so thin and abstract that it gives us no real system or ordering of telic principles. But, in response to this I have no option but to

52 When talking about moral telic principles, for instance, Murdoch says, "I have spoken of a process of deepening or complicating, a process of learning, which may take place in moral concepts in the dimension which they possess in virtue of their relation to an ideal limit" (1971: 31).

${ }^{53}$ An argument to the effect that this is the correct specification of the ideal limit of telic principles is too ambitious for the purposes of this paper. What serves my purposes here is the mere possibility that such an argument can be given.

${ }^{54}$ See (1971: 33-41), where Murdoch talks about the reality of the other as the ideal limit of perfection, but also (1971: 63-69), where she talks about the fantasy of the self and the way it obstructs the endless task of seeing the world as it really is. Elsewhere she says that "reality" and "individual" present themselves to us in moral contexts as ideal end-points" (1971: 41). 
remark, together with Murdoch, that "The scene remains disparate and complex beyond the hope of any system, yet at the same time the concept Good stretches through the whole of it and gives it the only kind of shadowy, unachieved unity which it can possess." ${ }^{5} 5$

Towards the end of section 2, I said that, on the neoAnscombean picture, the difficulty of some of our lives' most extended, unified and practically demanding projects is reduced either to the theoretical difficulty of figuring out what means manifest what ends, or to the technical difficulty involved in the execution of a plan. I can say now that the difficulty of some of our lives' most extended, unified and practically demanding projects is the practical difficulty of perfecting, and figuring how to perfect, the principles which govern some of our infinite activities (instrumental unities of means with infinite ends). For instance, the difficulty of the project of sharing my life with you is the practical difficulty of perfecting, and figuring how to perfect, the principle of companionship in our lives.

Thus, I think that following the spirit of Murdoch's account of perfection as central to the notion of the practicable good (to the notion of telic principles, in my terminology) allows us to make sense of the progressive achievement of an infinite end in the activity of pursuing it. And this in turn makes room for the idea that the activity of pursuing this infinite end may in fact progressively diminish the distance between oneself and one's end in the way that instrumental means do with finite ends-e.g., in the way that putting one foot in front of the other progressively diminishes the distance between me and my end of walking to the store. And thus we may come to see that the NeoAnscombean Assumption is false and that the instrumental principle may apply to unities of means with infinite ends.

${ }^{55}$ Murdoch (1971: 94-95).

Manuscrito - Rev. Int. Fil. Campinas, v. 41, n. 4, pp. 349-388, Oct-Dec. 2018. 
In the next section, I will give a Murdochian account of the instrumental principle.

\section{A MURdochian ACCOUNT OF THE INSTRUMENTAL PRINCIPLE}

\subsection{THE INSTRUMENTAL REQUIREMENT AS CONSTITUTIVE OF UNITIES OF MEANS WITH BOTH FINITE AND INFINITE ENDS}

In the first two sections of this paper I argued that the neo-Anscombean account of the instrumental principle is too restrictive, for it ignores intentions whose function is to enable the agent to keep things going as opposed to getting them done. But I argued in the third and fourth section that if we follow the spirit of Murdoch's Insight, we may make sense of the unfolding of an activity which constitutes the progressive achievement of an infinite end. And so we may understand the instrumental requirement in this case as the requirement that prescribes the unfolding of one's activity. But the requirement in this case is neither the requirement to get an end completed/executed/satisfied, nor the requirement to manifest/instance/exhibit an end that is fully determinate. The requirement in this case is the requirement to progressively determine one's end. Following the initial formulation of the consitutivist account of the instrumental requirement in the first section of this paper, we may say that, in these cases, the requirement to progressively determine one's end is what enables the agent to progressively determine the telic principles that guide the unfolding of one's infinite activity; i.e. what enables the agent to perfect her infinite activity. In other words, in these cases, the instrumental requirement is the (intention) constitutive principle that allows intention to serve the function of enabling the agent to perfect one's infinite 
activity.

But, even if this explanation of the above cases is right, the question arises: How can my account explain the applicability of the instrumental requirement to unities of means with merely finite ends that do not trace to an infinite source? The neo-Anscombean account has the resources to explain this: taking the means to a finite end is instrumentally required in light of facts about the metaphysics of intentional action as a process (finite activity). One strategy for answering this challenge would be to deny that it is ever possible to intend a finite end that does not trace to an infinite source. Think of Graham, who is taking the means to walk to the corner store in his neighborhood. Why? He just wants to see Lucy's face; he is smitten with her. Is this a shorthand way of saying that Graham intends to act in light of the principle of love? We can imagine Graham saying, "No, I just want to see her face." Could it be, then, that what drives Graham to take the means to his end is the principle of pleasure? Again, we can imagine Graham responding, "It's not love or pleasure or any of those things. All I want is to see her face for a moment. Then I'll be satisfied." Of course I could choose my pet theory over Graham's statements, but I think that I do not need to do so. I can admit the possibility that Graham intends to do what it takes to walk to the corner store, and that the telic principle which constitutes his consideration for doing so as his value in acting intentionally is finite. The moment Graham sees Lucy's face is the moment Graham's activity is fully done. But what does it mean to say that, in this case, Graham's activity is fully done? It is conceivable that Graham may achieve the end of his activity (walk to the store) without embodying his value in acting intentionally (see Lucy's face); perhaps it just so happens that, on this particular day, Lucy is away. Thus, for his activity to be fully done, Graham must, in getting his end done (walking to the store), be embodying 
the value he sees in taking the means to his end. Thus, to realize one's intention, it is not sufficient that one gets one's end done. One must get one's end fully done: that is, in having gotten one's end done one must have embodied the value one sees in taking the means to one's end. But this, the requirement to get one's end fully done, is what enables the agent to perfect one's activity of getting one's end done. Perhaps in our example this involves doing things such as calling at the store ahead of time to see whether Lucy answers the phone.

Given this explanation of the finite case, we may now give the following disjunctive definition of the instrumental principle:

Murdochian Constitutivist Definition: The instrumental principle is the requirement which normatively constitutes a means-end unity as perfectible activity. And an activity is perfectible either when the telic norm it embodies may be full determined by the activity of pursuing its finite end (walking to the store) or when the telic norm it embodies may be progressively determined by the activity of pursuing its infinite end (sharing my life with you).

Therefore, on the Murdochian Constitutivist Definition, to be doing A intentionally is to be committed to perfecting a perfectible activity (either by getting one's end fully done or by progressively realizing one's end). And if to be doing A intentionally is to be committed to perfecting a perfectible activity, and if $M$ is the necessary means to perfecting $\mathrm{A}$, then to fail to do $\mathrm{M}$ is to fail to perfect $\mathrm{A}$ and so to fail by the standards of what counts as exercising well one's capacity to intend or act intentionally. And so it flows from the function of intentional action as what enables the 
agent to perfect her activity that one ought to take the means to one's ends.

\subsection{CONCLUSION: THE IRREDUCIBILITY OF THE INSTRUMENTAL PRINCIPLE}

I suggested above that the instrumental requirement is the normative principle which constitutes intentional action as perfectible activity. And on the constitutivist picture I outlined in section 1.1 of this paper, this must mean that the instrumental requirement is what allows intention to serve its function. And so that the instrumental requirement is what enables the agent to either fully or progressively realize the value embodied in one's intentional action. What remains to be seen, though, is how this Murdochian account does justice to the introduction's three intuitions concerning instrumental normativity.

In the introduction, I also said that on the third intuition concerning instrumental normativity and telic norms are practical. And I suggested in the fourth section of the paper that the practicality of telic principles is not restricted to their efficacy; but that these principles are practical in the further sense that they are determined by the reality and the knowledge that the historically determined concrete human activity they govern gives rise to. I can say now that the practicality of the instrumental norms is the efficacy involved in the very idea of intention. If what I've said in this paper is right, then this is the efficacy of one's commitment to the full or progressive determination of telic principles. Thus, the normativity of the instrumental principle is explained in terms of the metaphysics of telic principles and not any one particular telic principle. On this explanation, the instrumental principle is normative because telic principles are such as to be fully determinable in the completion of a finite end and progressively determinable 
in the unfolding of the activity of pursuing an infinite end. The idea is not that the instrumental principle is normative because a telic principle is normative, but that the instrumental principle is normative because telic principles are such as to grow in the unfolding of the activity that embodies it.

This idea allows us to explain the normativity of the instrumental principle without reducing it to the normativity of telic requirements, as the neo-Kantian variety of constitutivism assumes. And, thus, we may do justice to the intuition that the instrumental principle may apply even if it may not be traced back to a telic principle. To see this more clearly consider the following example. Say that Robert intends to remain silent in the face of injustice in order to save his job, and that he does so in the light of prudence. But now say that Robert is mistaken and prudence does not actually demand that it be determined in the circumstances, because the action that is mistakenly taken by Robert to be its determination in the circumstances actually constitutes part of the injustice (if, for instance, silently consenting to injustice is itself part of the injustice). ${ }^{56}$ In this case, to save the phenomena, I would have to say that Robert is still subject to the instrumental requirement. But on my account the instrumental requirement is the requirement to either fully or progressively determine the value embodied in taking the means to one's end. And so the instrumental requirement in this case is the requirement to progressively determine the value of prudence in the circumstances. But, by the definition of the case, the requirement of prudence is not the requirement to remain silent in order to save one's job; for to do so in the circumstances would be part of the

${ }^{56}$ I'm assuming here Wiggins' and McDowell's view of what it is for a telic principle to apply to particular circumstances (see Wiggins 1987 and McDowell 1979). 
injustice and so not what prudence demands. And so, the objection goes, I may not say that in remaining silent in order to save his job Robert is meeting the instrumental requirement-for he is not. (This would be true only if it were indeed true that, in taking the means to his end, the agent would thereby be progressively determining the value he would see in doing so.) But, what I can say is that Robert is nevertheless still subject to the requirement to progressively determine the value of prudence in the circumstances, exactly because this requirement has its source in the nature of intending (committing to the progressive determination of the value one sees in taking the means to one's end; i.e. commitment to perfection of one's activity) and not in any particular value (and so in the value of prudence itself).

But, one might remark that realizing the value of prudence in the circumstances is something that, by my definition of the case, cannot actually be done (for remaining silent in the circumstances would be unjust). And so in saying that Robert is subject to the instrumental requirement I must be saying that one may be under a requirement that cannot be met; or else that one may intend something that cannot be done. But can I really say this? Is it not a flaw in a theory of intentional action if it allows intentions for things that are beyond one's power? But the fact that Robert is under a requirement that cannot be met is not a flaw in my account but a flaw in Robert's intending. In other words, on my account, when the agent mistakenly intends a means-end unity as embodying a certain value (in this example, intends to remain silent to save his job in the face of injustice for the sake of prudence), one not only fails by the lights of the particular value that ought to be realized in the circumstances (by the lights of justice, let's say), but one also fails by the lights of what it is to intend. For, in such circumstances, one intends something (to perfect a certain activity in certain 
circumstances) that cannot be done. That is, one places oneself under an instrumental requirement that cannot be met. And this failure is distinct from, and irreducible to, although related to the failure to do as telic principles command (e.g. the failure to do as justice commands).

\section{REFERENCES}

Aristotle. De Anima. Translated by D. W. Hamlyn. Oxford: Clarendon Press, 1993. Eudemian Etbics. Translated by H. Rackham. Cambridge, Mass.: Harvard University Press, 1952. Nicomachean Ethics. Translated by H. Rackham. Cambridge, Mass.: Harvard University Press, 1939. Anscombe, G. E. M. Intention, Second Edition. Ithaca: Cornell University Press, 1957.

Bedke, M. "The Iffiest Oughts: A Guise of Reasons Account of End-Given Conditionals". Ethics 119(4): 672-698, 2009.

Broome, J. "Normative Requirements". Ratio 12: 398-419, 1999.

"Normative Practical Reasoning". Proceedings of the Aristotelian Society, Supplementary Volume 75(1): 175193, 2001.

"Practical Reasoning", in J. L. Bermúdez and A. Millar (eds.), Reason and Nature: Essays in the Theory of Rationality. Oxford: Oxford University Press, 2002. "Reasons", in R. J. Wallace, P. Pettit, S. Scheffler and M. Smith (eds.), Reason and Value: Themes from the Moral Philosophy of Joseph Ra\%. Oxford: Oxford University Press, 2004.

"Does Rationality Give Us Reasons?". Philosophical Issues 15(1): 321-337, 2005.

"Wide or Narrow Scope?". Mind 116 (462): 359370, 2007. 
Brunero, J. “Are Intentions Reasons?”. Pacific Philosophical Quarterly 88(4): 424-444, 2007.

—The Scope of Rational Requirements". The Philosophical Quarterly 60(238): 28-49, 2010.

"Instrumental Rationality, Symmetry and Scope". Philosophical Studies 157(1): 125-140, 2012.

Clark, P. "Velleman's Autonomism". Ethics 111(3): 580593, 2001.

Comrie, B. Aspect. Cambridge: Cambridge University Press, 1976.

Dancy, J. Practical Reality. Oxford: Oxford University Press, 2000.

Kolodny, N. “Why Be Rational?”. Mind 114(455): 509-563, 2005.

"How Does Coherence Matter?". Proceedings of the Aristotelian Society 107(1): 229-263, 2007a.

"State or Process Requirements". Mind 116 (462): 371-385, 2007b.

"The Myth of Practical Consistency". European Journal of Philosophy 16(3): 366-402b, 2008a.

"Why Be Disposed to Be Coherent?". Ethics 118(3): 437-463, 2008b.

Korsgaard, C. M. "The Normativity of Instrumental Reason", in G. Cullity and B. Gaut (eds.), Ethics and Practical Reason. Oxford: Oxford University Press, 1997.

The Constitution of Agency: Essays on Practical Reason and Moral Psychology. Oxford: Oxford University Press, 2008.

Kosman, A. The Activity of Being; An Essay on Aristotle's Ontology. Harvard: Harvard University Press, 2013.

Lindeman, K. (unpublished) Constitutivism without Thresholds.

Murdoch, I. The Sovereignty of Good. New York: Routledge and Kegan Paul, 1971.

McDowell, J. "Virtue and Reason". The Monist 62(3): 331350, 1979. 
"Some Issues in Aristotle's Moral Psychology". Ethics 4: 107, 1998.

Raz, R. J. "The Myth of Instrumental Rationality". Journal of Ethics and Social Philosophy 1(1): 2-28, 2005.

Railton, P. "On the Hypothetical and Non-Hypothetical in Reasoning about Belief and Action", in G. Cullity and B. Gaut (eds.), Ethics and Practical Reason. Oxford: Oxford University Press, 1997.

Rödl, S. Self-Consciousness. Cambridge, MA: Harvard University Press, 2007.

Schroeder, M. "The Scope of Instrumental Reason". Philosophical Perspectives 18(1): 337-364, 2004.

"Weighting for a Plausible Humean Theory of Reasons". Noûs 41(1): 110-132, 2007.

"Means-End Coherence, Stringency and Subjective Reasons”. Philosophical Studies 143(2): 223-248, 2009. "Ought, Agents and Actions". The Philosophical Review 120(1): 1-41, 2011.

Setiya, K. "Is Efficiency a Vice?". American Philosophical Quarterly 42(4): 333-339, 2005.

"Cognitivism About Instrumental Reason". Ethics 117(4): 649-673, 2007.

Thompson, M. Life and Action, Elementary Structures of Practice and Practical Thought. Cambridge, Mass: Harvard University Press, 2008.

Valaris, M. "Instrumental Rationality". European Journal of Philosophy 22(3): 443-462, 2014.

Vogler, C. Reasonably Vicious. Cambridge, Mass: Harvard University Press, 2002.

"The Instrumental Structure of Actions". The Philosophical Quarterly 65(258): 64-83, 2015.

Wallace, R. J. "Normativity, Commitment and Instrumental Reason". Philosophers' Imprint 1(3): 1-26, 2001. 
Way, J. "Defending the Wide-Scope Approach to Instrumental Reason". Philosophical Studies 147(2): 213-233, 2010.

"The Symmetry of Rational Requirements". Philosophical Studies 155(2): 227-239, 2011.

Wiggins, D. Needs, V alues, Truth. Oxford: Blackwell, 1987.

Wiseman, R. Anscombe's Intention. London and New York: Routledge, 2016. 